\title{
The QALY argument: a physician's and a philosopher's view
}

\author{
John Rawles, Kate Rawles Department of Medicine and Therapeutics, University of Aberdeen, \\ and Department of Philosophy, University of Glasgow, respectively
}

\section{Authors' abstract}

The arguments used by Gavin Mooney in his scornful response to Castigating QALYs, $(1,2)$ are examined. In spite of the rhetoric there is a broad measure of agreement about the deficiencies of $Q A L Y$ s as a means of distributing scarce resources. The main area of conflict is that fohn Rawles favours campaigning for more resources while Gavin Mooney, constrained by his remit as a health economist, favours acceptance of the present level of funding and better methods of distributing resources.

\section{A physician's view}

'From William's estimates some very clear priorities are established for the allocation of NHS resources. If a district had $1 \mathrm{~lm}$ growth money ... its managers would recognise that it could produce 5988 QALYs from advice by general practitioners to stop smoking, 1333 QALYs from hip replacements, and 71 QALYs from hospital dialysis. Clearly, a health authority wishing to maximise QALYs would invest its $£ 1 m$ in advice by general practitioners to stop smoking ... . Some health authorities are using this approach to help in decisions about allocating resources' (3).

It was this pronouncement by "Maynard that prompted me to write 'Castigating QALYs' (2). Now, ideas, such as 'value for money', 'internal market', and 'QALYs' are every bit as powerful as drugs when applied to life-and-death situations, such as the distribution of health service resources. Before a powerful new idea is widely applied it should be subject to as much scrutiny, testing, and clinical trial as a new drug. The mode of action, efficacy, side-effects, risk-benefit ratio, and cost should all be ascertained in pilot studies before the idea is applied generally. Gavin Mooney professes difficulty in seeing what are my fundamental objections to QALYs (1). I have no fundamental objections to the idea of attempting to measure the outcome of health care, but strong objections to the premature, reckless, and irresponsible use of QALYs for decision-making. None of the basic assumptions and implications have

\section{Key words}

QALY; value of life; equity; value for money. been made explicit, and not even the monetary calculations have been published for all to see. I take $\vec{\sigma}$ particular objection to the use of QALYs for is comparing the outcome of fatal and non-fatal diseases because, when using the QALY measure, the implied monetary value of life is zero. Hence the nonsensical conclusions exemplified in the quotation above. A very different rank order of QALYs-for-money would have been achieved if a nominal monetary value for life had been used in the calculations, say $£ 0.5 \mathrm{~m}$. This is the value used by the Department of Transport when performing a cost-benefit analysis of re-engineering an accident blackspot (4). Other values could have been used, but the results using different assumptions should have been published, and the workings revealed.

Gavin Mooney quotes Dowie: 'The QALY is a symbol of the intention to tackle this horrifying task in an analytically explicit fashion and quantitatively, rather than covertly, qualitatively and intuitively'. Maynard's and Williams's endorsement of the use of QALYs by health authorities is frighteningly premature. The QALY only symbolises an intention, it is not a tool that has been tempered and honed by heated argument and abrasive criticism; it should not yet be used for decision-making.

\section{A philosopher's view}

In order to clarify and understand certain ethical principles, great ingenuity is often exercised in contriving hypothetical situations that put such principles to the test. Such a test case might be taken from the quotation from Maynard above (3): 'You are a health service manager with $\mathrm{flm}$ new money to spend. You may either spend it on anti-smoking advice, hip replacement or hospital dialysis. Which would you choose? Discuss the reasons for your decision.'

John Rawles, while recognising that there is an ethical problem here, does not attempt a solution. Rather, from his position as a physician he sees that the choice between treating certain fatal and non-fatal conditions is contrived and need not be faced immediately. If total resources are modestly increased such a difficult choice can be evaded.

On the other hand, Gavin Mooney, while also 
recognising the ethical problem, and agreeing that QALYs are flawed - their use to apportion resources leading to inequity - does not support an increase of resources. His remit, as a health economist, is to undermine doctors' authority and constrain their spending. He cannot afford to ally himself with the doctors, the big spenders. If he were to do so, and if the unlikely alliance of doctors and health economists were successful in persuading government to increase total spending on health care, there would no longer be a need for health economists. He would have worked himself out of a job, an outcome that no doctor ever has to fear.

\section{MOONEY'S STRAW MEN PLOY}

Mooney claims that he cannot see what Rawles's objections to QALYs are, but then discusses some possibilities, only to knock them down.

1. He makes great play of management by shroudwaving (MSW). But Rawles did not advocate shroudwaving as a normal method of management, only as a last resort. 'If facilities are totally inadequate he may indulge in shroud-waving, ie announcing publicly that unless resources are increased patients will suffer and die unnecessarily' (2). Indeed, Rawles indicates that he accepts the principle of measuring the need for health care, with a strong weighting for life-threatening conditions: 'A more equitable system of rationing health care would be based on need, need being assessed by the degree of suffering, with prolongation of life having overriding priority'.

2. Neither is Rawles 'indiscriminately critical of QALYs'. His criticisms of QALYs as used by Maynard and Williams are highly specific - the implied value of life is zero, and the distribution of resources by valuefor-money is inequitable.

3. Mooney, in his 'simple example' demonstrates that Rawles's theory of justice is expensive in terms of death and suffering, and suggests that Rawles would be prepared to sacrifice 100 lives in the cause of justice. But Rawles nowhere said that patients should be selected for life-saving treatment by some sort of lottery. Faced with a severe shortfall of resources he would go a-shroud-waving.

\section{THE BASIC PREMISE OF HEALTH ECONOMICS}

The subject of health economics takes as its starting point the mismatch between supply and demand, 'the ubiquitous nature of scarcity' (3). So often has it been said that the demands for health care are infinite while resources are finite, that this basic premise of health economics is accepted as true. Rawles is at pains to point out that, while in an absolute sense this may be so, in Britain in 1990, a developed country with a strong economy, the demand for health care is far from infinite, and society's resources though finite, are adequate to meet those demands. No one needs to be denied life-saving treatment because of lack of funds.
The decision to limit resources so that reasonable requirements for health care are not met stems from a particular political ideology, of which health economics may be seen as a tool. Any attack on the very foundation stone of health economics must necessarily be shaken off by practitioners of the subject, who have a vested interest in scarcity.

\section{WHO SHOULD SET PRIORITIES?}

Mooney points out that it is society's resources that are used in health care, and that society has not clearly delegated the task of priority setting to the doctors. However, society certainly has not delegated this task to health economists. Neither would the public's confidence in the ability of health economists to set priorities be helped by the knowledge that health economists are indifferent to whether or not a disease is life-threatening. Doctors are at least seen to be waving shrouds on behalf of patients whose lives are threatened.

\section{Conclusions}

In spite of the rhetoric there is a broad measure of agreement between Rawles and Mooney. They are agreed that a method of measuring the outcome of health care is desirable, and that QALYs, as they stand, are not enough. They are agreed that distribution of resources by value-for-money is inequitable. Neither has a solution to the ethical problems posed by scarcity of resources; both agree that solutions should be sought.

The main area of disagreement is what the response to the present underfunding of the health service should be. Rawles favours campaigning for more resources; Mooney favours acceptance of the present level of funding, greater efficiency in its use, and the development by health economists of fairer methods of denying patients treatment.

Fohn Rawles BSc FRCP is Senior Lecturer in Medicine, Department of Medicine and Therapeutics, University of Aberdeen, Foresterhill, Aberdeen AB9 2ZD. Kate Rawles MA is a Postgraduate Student in the Department of Philosophy, University of Glasgow. Correspondence to Fohn Rawles.

\section{References}

(1) Mooney G. QALYs: are they enough? A health economist's perspective. Fournal of medical ethics 1989; 15:148-152.

(2) Rawles J M. Castigating QALYs. Fournal of medical ethics $1989 ; 15: 143-147$.

(3) Maynard A. Logic in medicine: an economic perspective. British medical journal 1987; 295:1537-1541.

(4) Anonymous. Value of life to increase. British medical journal 1988; 297:299. 